\title{
Natriuresis y hemodinámica glomerular en un incomprendido sistema renina angiotensina aldosterona
}

\author{
Natriuresis and Glomerular Hemodynamics in misunderstood Renin-angiotensin-aldosterone system \\ Edwin Roland ${ }$ Castillo ${ }^{1, a}$ \\ RESUMEN
}

La respuesta natriurética y la hemodinámica glomerular dependen de diversos sistemas de regulación intrarrenal; sin embargo, la mayoría de ellos posee algún grado de dependencia del sistema renina angiotensina. La distribución tisular y el efecto hemodinámico de este sistema son de vital importancia para el entendimiento de la regulación natriurética y del filtrado glomerular en diversas enfermedades que se caracterizan por desregulación del equilibrio del sodio o del filtrado glomerular, tales como el síndrome nefrótico, la falla renal aguda y crónica e hipertensión arterial.

PALABRAS CLAVE: Natriuresis, sistema renina-angiotensina, tasa de filtración glomerular. (Fuente: DeCS BIREME)

\section{SUMMARY}

Natriuretic response and glomerular hemodynamics depend on various intrarenal regulation systems; however, most of them possess some degree of dependence on the renin-angiotensin system. Tissue distribution and hemodynamic effects of this system are of vital importance for understanding of the natriuretic and glomerular filtration regulation in the context of different diseases characterized by dysregulation of sodium balance or glomerular filtration rate, such as nephrotic syndrome, acute and chronic renal failure and hypertension.

KEY WORDS: Natriuresis, glomerular filtration rate, renin-angiotensin system. (Source: MeSH NLM)

\section{INTRODUCCIÓN}

El filtrado glomerular aporta 4000 milimoles de sodio al día para su procesamiento en los túbulos. De esa cantidad el $98 \%$ es reabsorbido, y el resto representa la carga natriurética normal (1). Cambios entre la carga filtrada y la fracción de sodio reabsorbido pueden ejercer una profunda influencia acumulativa en el equilibrio global del sodio. Existen diversos factores hemodinámicos tisulares que regulan esta carga natriurética, como el sistema renina angiotensina intrarrenal (2).
Es necesario un conocimiento molecular y hemodinámico de este sistema, para evaluar su impacto en enfermedades que cursan con retención primaria de sodio como el síndrome nefrótico, o cambios en la hemodinámica glomerular y sus consecuencias como en la falla renal aguda y crónica, o la interacción entre la ingesta de sal, distribución tisular y hemodinámica glomerular en la hipertensión arterial. Con este discernimiento, es posible ver la implicancia de la inhibición terapéutica de este sistema. 


\section{Natriuresis y filtrado glomerular}

En general, cuando el volumen del líquido extracelular se mantiene constante, un aumento en el filtrado glomerular (FG), produce un escaso o nulo aumento en la excreción de sodio. En cambio cuando el volumen del líquido extracelular se encuentra expandido, se produce grandes incrementos en la excreción de sal, incluso en presencia de un FG reducido. Sin embargo, la expansión masiva de volumen con albúmina hiperosmótica no necesariamente incrementa la natriuresis, lo cual indica un mecanismo de regulación intrarrenal para el ajuste natriurético, como la reabsorción distal de sodio. En este sentido, entre los mecanismos de ajuste natriurético se conoce el feedback túbulo-glomerular, el cual induce vasodilatación de las arteriolas aferentes, e hiperfiltración como respuesta a una menor concentración de sodio a nivel distal $(1,3)$.

\section{Factores reguladores de la natriuresis}

Entre los diferentes sistemas que intervienen en la modulación de la relación presión-natriuresis, tenemos la actividad del sistema renina angiotensina aldosterona (RAAS, en inglés) y la producción local de prostaglandinas. El uso de inhibidores de la enzima convertidora de angiotensina (ECA) o de inhibidores del receptor de la angiotensina (ARA), potencian la natriuresis, mientras que el uso de inhibidores de la ciclo oxigenasa la atenúa (1).

Las cininas también modulan la respuesta natriurética. El sistema cinina-kalikreina, produce concentraciones locales de bradicinina mucho más alta que en el plasma. Poseen 3 receptores, de los cuales los B2 median sus acciones principalmente en el riñón, en donde produce vasodilatación, en un probable mecanismo dependiente de oxido nítrico. La bradicinina aumenta el flujo plasmático renal sin afectar significativamente el filtrado glomerular, ni la reabsorción proximal de sodio, sin embargo disminuye la reabsorción de agua y sal a nivel distal, con lo cual incrementa la natriuresis. Este sistema interacciona con el sistema renina angiotensina, ya que la enzima convertidora de angiotensina (ECA), favorece la degradación de las cininas, con lo cual se atenúa el efecto vasodilatador y natriurético. Asimismo, la angiotensina II se asocia a la deficiencia de bradicinina y óxido nítrico (3-9).

Adicionalmente, otro sistema como el dopaminérgico intrarrenal es también responsable de más de la mitad de la respuesta natriurética en estados de repleción de sal, al inhibir la reabsorción de sodio en el túbulo proximal, a través de su interacción con el receptor tipo 2 de angiotensina II (AT2) $(2,5,9)$.

\section{Sistema renina angiotensina}

El sistema renina angiotensina es considerado como un sistema dual (circulante y tisular) cuyas acciones son endocrina, paracrina y autocrina. Por ejemplo, el 90-99\% de la ECA se encuentra a nivel tisular, y solo el $1 \%$ a nivel circulante. La angiotensina II (AII) puede expresar una respuesta hemodinámica sistémica, a través de sus receptores de superficie, lo cual ocurre en segundos o minutos. Ejerce también un efecto de transcripción génica intracelular cuya respuesta incluye efectos mitogénicos y de proliferación celular, los cuales ocurren desde horas, semanas a meses. No todos los bloqueadores de receptores de angiotensina, o inhibidores ECA poseen el mismo bloqueo extra o intracelular de AII (10-12,13).

\section{Sistema renina angiotensina tisular intrarrenal}

La angiotensina II es secretada en la luz epitelial proximal de la nefrona, lo que provoca una alta concentración en aproximadamente 1000 veces más que en plasma. No obstante a ello, el riñón es muy sensible a sus acciones, pues se requieren solo concentraciones picomolares para evidenciar cambios en la hemodinámica intrarrenal, a diferencia de las concentraciones con las que se observan sus efectos extrarrenales, que son 10 a 100 veces más (12). Entre sus acciones intrarrenales directas se conoce la reabsorción neta de sodio proximal al activar bombas como $\mathrm{Na} / \mathrm{H}$, la expresión de $\mathrm{NHE} 3$, de la $\mathrm{Na}-\mathrm{K}-$ ATPasa, y la modulación de la presión-natriuresis en el túbulo proximal $(9,14,15)$. Asimismo, entre los efectos nocivos de la angiotensina se conoce la formación del anión superóxido, en la cascada oxidativa (16).

\section{Receptores de angiotensina}

De los diversos tipos de receptores de angiotensina descritos hasta el momento, el receptor AT1 sigue siendo el principal y el que se relaciona con la reabsorción proximal de sodio. El receptor AT2 es expresado en mayor nivel en el feto, pero declina su valor en la mayoría de tejidos en el periodo neonatal. El principal agonista del receptor AT2 es la AII, sin embargo, la distribución de este receptor es menor, y a nivel renal se encuentra restringida a segmentos vasculares y tubulares, en especial en el túbuli 
proximal. En los podocitos, se expresan ambos tipos de receptores, y a nivel experimental, se ha descrito su importancia en la nefropatía diabética, en donde la incubación de los receptores AT2 con los productos de glicación avanzada (AGE) favorece la expresión de los receptores de los productos de glicación avanzada (RAGE), lo cual está implicado en la apoptosis podocitaria y mecanismos pro-inflamatorios. Este proceso, es estimulado a su vez, por el incremento renal de AGE, secundario a la infusión de AII $(2,17,18)$.

\section{Prorenina}

Constituye un precursor inactivo de renina, cuyo receptor, a nivel renal es expresado en los podocitos. La prorenina, es producida también por órganos extrarenales como las glándulas adrenales, gónadas y retina. Tanto renina como prorenina poseen afinidad por el mismo receptor y la misma señal intracelular; asimismo, favorece el aumento del nivel de Factor de crecimiento transformante beta (TGF-beta). En los estudios in vitro, se requieren de concentraciones nanomolares de prorenina para su activación, sin embargo, solo concentraciones fentomolares $\mathrm{o}$ picomolares son encontradas fisiológicamente, por lo que su rol no está bien establecido $(14,15,19)$.

\section{Angiotensinógeno}

Es sintetizado a nivel de las células tubulares proximales. Es eliminado en orina como forma intacta por no ser degradado en la nefrona. Se ha descrito su incremento en orina, en pacientes con hipertensión arterial $(14,15,19)$.

\section{Enzima convertidora de angiotensina}

Se localiza primariamente a nivel de la membrana en borde en cepillo del túbuli proximal. Se reconoce al momento una isoforma de la ECA, la ECA-2, la cual se expresa además en el glomérulo, células musculares lisas vasculares y endoteliales a nivel de las arterias intrarenales. Es responsable de procesar angiotensina I (AI) a angiotensina 1-7, la cual posee acciones opuestas a la AII, como vasodilatación o efectos anti proliferativos. La Angiotensina 1-7 puede también ser producida por la nefrilisina, que es otra enzima responsable de su procesamiento desde la AI (1,3-8). La ECA-2, no es inhibida por los inhibidores ECA, lo cual demuestra su mecanismo independiente $(14,15,19)$.
Considerando los aspectos hemodinámicos y distribución tisular de la angiotensina, se consideran a continuación las siguientes enfermedades.

\section{SINDROME NEFRÓTICO}

\section{Efecto natriurético y hemodinámico}

Es conocido que los pacientes adultos con síndrome nefrótico como consecuencia de una reabsorción primaria de sodio a nivel tubular, cursan con hipervolemia (teoría overfilling), lo cual ha sido demostrado en razón a varios argumentos, como el incremento del péptido natriurético atrial secundario a esta expansión de volumen. En este caso, los factores intrarrenales responsables de la reabsorción tubular de sodio, asociados al sistema renina angiotensina, se relacionan al incremento en la actividad de la bomba $\mathrm{Na} / \mathrm{H}$ en el túbulo proximal y de la bomba $\mathrm{Na} / \mathrm{K} /$ ATPasa en el túbulo colector $(20,21)$.

Como consecuencia de la hipervolemia, se puede encontrar los niveles de renina plasmática suprimidos, $y$ en este sentido se debe diferenciar el rol del sistema renina angiotensina circulante y tisular. El uso de IECA en la retención primaria de sodio del síndrome nefrótico favorece la natriuresis como efecto del bloqueo tisular, pero posee una repercusión hemodinámica adicional asociado al bloqueo circulante, que debiera tenerse en consideración en casos de síndrome nefrótico severo asociado a disminución del filtrado glomerular. Para un mejor entendimiento de las consecuencias del bloqueo hemodinámico, se debe considerar su efecto en el filtrado glomerular en dos situaciones: falla renal aguda y crónica.

\section{FALLA RENAL AGUDA}

\section{Efecto hemodinámico}

Si bien posee diversa etiopatogenia, es conocido que como consecuencia de la menor presión de filtración glomerular ocasionada por el uso de los IECA puede existir una menor perfusión intrarrenal, que se exacerba en situaciones de deshidratación en donde no se ha suspendido esta medicación. Por lo que puede ser un factor agravante en una necrosis tubular aguda. Además se conocen diversos estudios, en donde la asociación de los IECA con bloqueadores de los receptores de angiotensina, ocasionan episodios de injuria renal (22). 
Por otro lado, en los pacientes con falla renal aguda asociada a sepsis, se reconoce que existe más bien un incremento de la presión de perfusión renal, que guarda correlación con el estado hiperdinámico o vasodilatado de estos pacientes. En este caso, la disminución del filtrado glomerular se relaciona más bien a una redistribución interna del flujo sanguíneo renal en el que existe una mayor vasodilatación de la arteriola eferente en relación a la aferente. En este sentido, la restauración del filtrado glomerular, dependería de la administración de angiotensina II, y su bloqueo sería contraproducente (23).

\section{FALLA RENAL CRÓNICA}

\section{Efecto hemodinámico}

Apesardelextendidousodelos IECAybloqueadores del receptor de angiotensina en la prevención de la nefropatía diabética, la incidencia de la misma sigue en aumento. Si bien es ampliamente conocido sus efectos en la reducción de proteinuria, y efectos pleiotrópicos en la progresión de la enfermedad renal crónica, sin embargo, se ha cuestionado su uso en especial su asociación, en pacientes con enfermedad renal crónica estadio IV. La disminución del filtrado glomerular se ha reportado en diversos estudios, por lo que en este caso se enfatiza la apreciación hemodinámica del bloqueo del sistema renina angiotensina frente a un filtrado glomerular reducido $(22,24,25)$.

\section{HIPERTENSIÓN ARTERIAL}

\section{Ingesta de sal y sistema renina angiotensina}

En diversos estudios se ha demostrado la reducción de la presión arterial asociado con la restricción de sal. Si bien la industria alimentaria menciona que la sal solo interviene en el $10 \%$ de la población hipertensa, en realidad, es al menos el $30 \%$ de la población mayor de 60 años que responde a una restricción de sal considerando las décadas de exposición. Lo cual no es de sorprender por el efecto que posee en el volumen extracelular, pues una reducción de 10 a $5 \mathrm{~g}$ genera una reducción del peso hasta de $1 \mathrm{Kg}$. La inhibición de la actividad de la renina plasmática ocurre frente a una ingesta diaria de 30 milimoles. Una ingesta de 50 milimoles al día suprime además la secreción de aldosterona casi por completo. Una dieta de $30 \mathrm{mmol}$ equivale a una alimentación proveniente en sus dos tercios de fuente vegetal y en un tercio de fuente animal sin sal añadida, lo cual equivale aproximadamente a
0,6 g y dista enormemente con los 10-15 g que puede ingerir actualmente la población, en razón a la gran cantidad de ingesta de comida procesada.

Por estas razones, la programación celular se orienta a una alimentación con cantidades de sodio consumidas naturalmente y no en forma añadida (26-28). Estos hallazgos, no deben de confundirse con los cambios agudos entre sobrecarga de sal y presión arterial, en donde el incremento del volumen extracelular no genera ningún incremento en la presión arterial, ya que existe una respuesta natriurética importante y más bien existe una disminución del sistema renina angiotensina (29).

\section{Efecto natriurético}

En la fisiopatología de la hipertensión sal sensible se ha reconocido el rol determinante del riñón. Inicialmente existen diversos factores predisponentes que generan una vasoconstricción preglomerular, lo cual disminuye la carga filtrada de sodio, y en consecuencia se incrementa su reabsorción primaria a nivel tubular, ocasionando un balance positivo de sodio. Posteriormente el restablecimiento del filtrado se asociará al incremento en la presión de perfusión renal para favorecer la natriuresis. Dicho proceso ocurre a expensas del incremento en la presión arterial sistémica con desviación de la curva presión/ natriuresis hacia la derecha $(16,30)$.

\section{Sistema renina angiotensina tisular}

Si bien en el corazón también existe un sistema renina angiotensina tisular, en donde la concentración de angiotensina II es 100 veces la del plasma, se ha demostrado experimentalmente que animales que no expresaban receptores 1 de angiotensina 2 (AT1) en forma sistémica, pero si a nivel renal, desarrollaban hipertensión severa e hipertrofia cardiaca inducida por angiotensina II, en forma similar a que si tuvieran dicho receptor sistémico. En cambio, cuando no expresaban el receptor AT1 a nivel renal no había evidencia de hipertensión ni de hipertrofia cardiaca inducida por angiotensina II. Estos hallazgos sugieren que la hipertrofia miocárdica no se encuentra en relación directa a las acciones de receptor AT1 a nivel cardiaco, sino es consecuencia de los efectos hemodinámicos y natriuréticos por los cambios patogénicos intrarrenales (31). Asimismo la presencia o no del receptor AT1 guarda correlación con el nivel excretado de sodio. 


\section{Efecto hemodinámico}

Los IECA o los bloqueadores del receptor de angiotensina tienen un uso extenso e importante en el tratamiento de la hipertensión arterial. Sin embargo, se debe considerar el efecto hemodinámico, cuyas consecuencias se pueden observar cuando coexiste disminución del filtrado glomerular en el tratamiento de la hipertensión arterial. En este sentido, el uso de los IECA como tratamiento antihipertensivo, ha reportado un incremento de hasta el 30\% del nivel sérico de creatinina en pacientes con enfermedad renal crónica de base, lo cual tiende a estabilizarse en los siguientes dos meses. En aquellos pacientes que además coexisten con falla cardiaca o aterosclerosis renal este incremento puede ser mayor al 30\%, y además pueden cursar con valores de potasio de más de 5,6 mmol/1, lo cual debe sugerir una reevaluación y posible discontinuación de este tratamiento (32).

\section{CONCLUSIONES}

El sistema renina angiotensina intrarrenal interviene en el ajuste de la natriuresis y en los efectos hemodinámicos en el filtrado glomerular. El sistema de las cininas y el dopaminérgico también regulan la natriuresis, pero en relación a la interacción con la angiotensina II. La AII posee una respuesta hemodinámica sistémica y otra tisular. Esta última, a nivel intrarrenal tiene una mayor concentración de AII que en el plasma, y entre sus principales efectos, permite la reabsorción proximal tubular de sodio a través de su receptor AT1. El síndrome nefrótico esquematiza la fisiopatología de dicha retención primaria de sodio.

Por otro lado, la AII circulante, sistémica, modula la hemodinámica glomerular. Una consecuencia de su inhibición, con el uso de los IECA, es la disminución de la presión de perfusión intrarrenal que se evidencia con una disminución del filtrado glomerular. Los episodios de injuria renal asociado al uso de estos fármacos, tanto en el contexto de una falla renal aguda o crónica, demuestran el impacto que posee la modulación hemodinámica de la AII.

En la hipertensión arterial, el consumo de sal disminuye la actividad del sistema renina angiotensina, sin embargo en la fisiopatología de la hipertensión sal sensible, se reconoce el papel determinante del riñón en la retención de sal a nivel tubular, lo cual condiciona el incremento de la presión arterial, y a su vez, ello determina la desviación de la cursa presión/ natriuresis a la derecha. Además, los receptores AT1 a nivel renal tienen mayor impacto en la hipertrofia cardiaca asociada a hipertensión arterial que los mismos receptores a nivel cardiaco.

Si bien es cierto que la protección cardiorenal derivada del bloqueo del sistema renina angiotensina es importante terapéuticamente por el efecto tisular inflamatorio, pro-oxidativo y antinatriurético de la angiotensina, sin embargo no puede soslayarse su acción hemodinámica. En el síndrome nefrótico, la generalización del bloqueo farmacológico en todos los contextos clínicos, dejaría de lado las consideraciones que intervienen en la perfusión renal y que podría agravarse en el síndrome nefrótico severo. En una falla renal aguda, si bien no tiene implicancia el uso de IECA, su utilización agravaría la misma. En la falla renal crónica e hipertensión arterial, los IECA son de uso reconocido, sin embargo deben de contextualizarse con cada paciente en razón al efecto hemodinámico intraglomerular que poseen.

\section{Declaración de conflicto de intereses:}

El autor declara no tener conflictos de intereses.

\section{Correspondencia:}

Edwin Rolando Castillo Velarde

Correo electrónico: edwin_castillo2002@yahoo.es

\section{REFERENCIAS BIBLIOGRAFICAS}

1. Brenner BM. Brenner y Rector. El Riñón. Tratado de Nefrología. 7ma edición. Madrid: Editorial Panamericana; 2005. p. 783-804.

2. Carey R. The intrarenal renin-angiotensin and dopaminergic systems: Control of renal sodium excretion and blood pressure. Hypertension. 2013; 61: 673-80.

3. McDonough A. Mechanisms of proximal tubule sodium transport regulation that link extracellular fluid volume and blood pressure. Am J Physiol Regul Integr Comp Physiol. 2010, 298: R851-61.

4. Susuki H, Saruta T (Editores). Kidney and Blood Pressure Regulation, Contributions to Nephrology. Basel: Ed Karger; 2004. p. 1-89, 117-131.

5. Rodriguez B, Romero F, Johnson R. Pathophysiological mechanisms of salt-dependent hypertension. Am J Kidney Dis. 2007; 50(4): 655-72.

6. Carey R, Padia S. Role of angiotensin AT2 receptors in natriuresis: Intrarenal mechanisms and therapeutic potential. Clin Exp Pharmacol Physiol. 2013; 22:1681-90. 
7. Sharma J. Hypertension and the Bradykinin system. Current Hypertension Reports 2009, 11:178-81.

8. Madeddu P, Emanueli C, El-Dahr S. Mechanisms of disease: the tissue kallikrein-kinin system in hypertension and vascular remodeling. Nature Clinical Practice Nephrology. 2007; 3(4): 208-21.

9. Castrop H, Ho Cherl K, Kurtz A, Schweda F, Todorov V, Wagner C. Physiology of kidney renin. Physiol Rev. 2010; 90: 607-673.

10. Abadir P, Walston J, Carey R. Subcellular characteristics of functional intracellular renin angiotensin systems. Peptides. 2012; 38:437-45.

11. Colucci W, Braunwald E. Pathophysiology of heart failure. En: Bonow R, Mann D, Zipes D, Libby P. Braunwald's Heart Disease, 9th edición. Philadelphia: Saunders, an imprint of Elsevier Inc; 2011. p. 614-43.

12. Kumar R, Baker K, Pan J. Activation of the reninangiotensin system in heart failure. En: Mann D. Mann: Heart Failure. 2th edición. Philadelphia: Saunders, an imprint of Elsevier Inc; 2011. p. 134-46.

13. Zhuo J, Li X. New insights and perspectives on intrarenal renin-angiotensin system: Focus on intracrine/intracellular angiotensina II. Peptides. 2011, 32:1551-65.

14. Fyhrquist F, Saijonmaa O. Renin angiotensin system revisited. J Intern Med. 2008; 264:224-36.

15. Rosivall L. Intrarenal rennin-angiotensin system. Molecular and Cellular Endocrinology. 2009; 302:185-192.

16. Oparil S, Zaman A, Calhoun D. Pathogenesis of hypertension. Ann Intern Med. 2003; 139:761-76.

17. Gurley S, Riquier A, Schnermann J. AT1a angiotensin receptors in the renal proximal tubule regulate blood pressure. Cell Metabolism. 2011; 13:469-75.

18. Kanwar Y, Wada J, Sun L. Diabetic nephropathy: Mechanisms of renal disease progression. Exp Biol Med. 2008; 233:4-11.

19. Crowley S, Coffman T. Recent advances involving the rennin angiotensin system. Experimental Cell Research. 2012; 318:1049-1056.

20. Orth S, Ritz E. The Nephrotic Syndrome. N Engl J Med. 1998; 338(17):1202-11.
21. Alcazar R, Lopez Gomez JM, Rivera F. Manejo general del sindrome nefrótico. Nefrología. 2007; 27(S2):15-32.

22. Krause M, Fonseca V, Shah S. Combination inhibition of the rennin-angiotensin system: is more better? Kidney Int. 2011; 80:245-55.

23. Bellomo R, Wan L, Langenberg C. Septic acue kidney injury: New concepts. Nephron Exp Nephrol. 2008; 109:e95-e100.

24. Ahmed A, Kamath N, El Kossi M. The impact of stopping inhibitors of the renin-angiotensin system in patients with advanced chronic kidney disease. Nephrol Dial Transplant. 2010; 25:3977-82.

25. Onuigbo M. Can ACE inhibitors and angiotensin receptor blockers be detrimental in CKD patients? Nephron Clin Pract. 2011; 118:c407-c419.

26. Karppanen H, Mervaala E. Sodium intake and hypertension. Prog Cardiovasc Dis. 2006; 49(2):5975.

27. Frisoli T, Schmieder R, Grodzicki T, Messerli F. Salt and hypertension: is salt dietary reduction worth the effort? Am J Med. 2012; 125(5):433-39.

28. Kotchen T, Cowley A, Frohlich E. Salt in health and disease. a delicate balance. N Engl J Med. 2013; 368:1229-37.

29. Bie P, Wamberg S, Kjolby M. Volume natriuresis vs pressure natriuresis. Acta Physiol Scand. 2004; 181:495-503.

30. Hall J, Granger J, do Carmo J, et al, Hypertension: physiology and pathophysiology. Compr Physiol. 2012; 2(4):2393-42.

31. Crowley S, Gurley S, Herrera M. Angiotensin II causes hypertension and cardiac hypertrophy through its receptors in the kidney. Proc Natil Acad Sci USA 2006; 103(47):17985-17990.

32. Bakris GA, Weir M. Angiotensin converting enzyme inhibitor associated elevations in serum creatinine. Arch Intern Med. 2000; 160:685-93.

Recibido: 23/02/2014

Aceptado: 07/07/2014 